\title{
BIOSYNTHESIS OF microRNAs AND THEIR ROLE IN GENE EXPRESSION PROFILING IN BREAST CANCER
}

Leonardo Barcelos DE PAULA ${ }^{1}$ Rodrigo da Silva SANTOS ${ }^{2}$

Angela Adamski da Silva REIS ${ }^{3}$

\footnotetext{
${ }^{1}$ Universidade de São Paulo - Faculdade de Medicina de Ribeirão Preto (USP-FMRP); Mestre em Biologia Celular e Molecular (USP-FMRP). E-mail: leobarcelosp@gmail.com

${ }^{2}$ Universidade de São Paulo - Faculdade de Medicina de Ribeirão Preto (USP-FMRP); Mestre em Biologia Molecular pela Universidade Federal de Goiás - Instituto de Ciências Biológicas (UFG-ICB).

${ }^{3}$ Universidade Federal de Goiás - Instituto de Ciências Biológicas (UFG-ICB); Professora Doutora pelo Departamento de Bioquímica e Biologia Molecular (UFG-ICB).
}

\begin{abstract}
The aggressive nature of breast cancer in young women may be related to the occurrence of mutations in the BRCA1/BRCA2 genes responsible for DNA repair. Despite of cases are associated with and without a family history of breast and ovarian cancer such changes are present in only a small percentage of cases, which corresponds to $80-10 \%$ of patients with familial breast cancer and 3.2-10.6\% of women with breast cancer non-familial (sporadic). The penetrance rate of this variability is not well understood today, but we know that reproductive factors, risks posed by particular mutations and other genetic modifiers The expression profile of miRNAs can also reveal changes in the regulatory processes that distinguish the appearance of cancer familial and sporadic breast cancer in young patients. miRNAs have been described as related to the aggressiveness of breast cancer and the sensitivity of human mammary tumor strains to antiestrogen. Such evidence indicates that the molecular mechanisms responsible for the aggressive behavior of breast carcinoma in young women has not been sufficiently clarified.
\end{abstract}

Keywords: breast cancer, microRNAs, genes BRCA1 and BRCA2. 


\section{Breast cancer and woman's reproductive life}

Breast cancer is one of the main diseases affecting the female population. The number of new cases of breast cancer in Brazil in 2010 was 49.240, with an estimated risk of 52 cases per 100.000 women (INCA, 2010). Risk factors associated with the development of breast cancer are related to the woman's reproductive life, such as early menarche, nulliparity, age at first pregnancy over 30 years, use of oral contraceptives, late menopause and hormone replacement therapy.

Besides these factors, age remains one of the most important risk factors (INCA, 2010) and is associated with two types of cancer: The first occurs early during premenopause, is characterized by the absence of estrogen receptor (ER-) and higher levels of aggression, the second type occurs during post-menopause and is related both to the presence of this receptor (ER+), as a lower level of aggressiveness (Gonzalez-Ângulo et al., 2005). Inside each group, there are morphological variations, such as medullar carcinomas in ER- tumors and tubular carcinomas and lobular ER+ tumors (Fernandopulle et al., 2006).

Breast cancer in young women is presented by patients of age or less for 35 years, mostly in the premenopausal women (Walker et al., 1996). Although this type of cancer is responsible for only $2 \%$ of cases of breast cancer, it presents more advanced at diagnosis, histological grade corresponding to a less differentiated (Gajdos et al. 2000; Sidoni et al. 2003; Foxcroft et al., 2004). The patients also have increased mortality and less disease free survival rate compared to postmenopausal patients (Bertheau et al. 1999; Joslyn, 1999). Anders et al. (2008) showed that tumoral gene expression profile shown by young women is different from that for postmenopausal women. Such evidence shows that differences in biological behavior of these tumors reflect distinct molecular mechanisms, which can be explained by the fact that the development of each of these tumors occur in different hormonal environments. 


\section{Gene expression and breast cancer}

The BRCA1 gene was mapped by Hall et al. (1990) from linkage analysis involving families with multiple cases of breast cancer, being cloned and characterized Miki et al. (1994). This tumor suppressor acts in very important cellular processes such as DNA repair by nucleotide excision, points of regulation of cell cycle control, protein ubiquitination, chromatin remodeling and silencing of the $\mathrm{X}$ chromosome (Wu, 1996; Buller, 1999 ; Xu, 1999; Bocher, 2000, Le Page, 2000; Wang, 2000; Hatman and Ford, 2002). In chromosome 17 (17q12-q21), this gene is composed of 81.155 base pairs (bp), the coding region is split into 22 exons with 5.592 bp (exons 1 and 4 are not translated). The encoded protein is composed of 1.863 amino acids with a motif of zinc-finger important for the degradation activity route ubiquitin ligase and interaction with other proteins in the amino-terminal region. Furthermore, we find two nuclear localization domains significant for interaction with proteins of cell cycle control, such as p53, a DNA binding domain (DNA binding domain) in the central region of the protein that allows to check the cell cycle, a SCD region (cluster of sequences important for serine and threonine phosphorylation of ATM and the region carboxy-terminal two BRCT domains made up of negatively charged amino acids and significant for maintaining the stability of the protein and cellular transcription processes (Miller, 1996; Wu, 1996; Scully, 1997a and 1997b; Deng and Brodie, 2000; Wang, 2000; Venkitaraman, 2002; Yarden, 2002; Narod and Foulkes, 2004).

The BRCA2 gene, whose mutations are responsible for $32 \%$ of inherited cases, was mapped by Wooster et al. (1994 and 1995) and featured in the following year by Tavtigian et al. (1996). It is located on chromosome 13 (13q12-q13), has 84.193 $\mathrm{bp}$, the coding region is split into 26 exons (exon 1 is not translated) comprising 10.254 base pairs and its protein is made up of 3.418 amino acids. In the N-terminal region of the protein is a nuclear localization signal and transactivation domain, which are followed by eight repeats (called BRC repeats domain) that include exon 11 almost entirely and are responsible for 
interaction with the $\operatorname{Rad} 51$ protein both act in the repair process of double breaks in DNA by homologous recombination. Further to, there is a DNA binding domain that binds single strand DNA and C-terminal region, with a binding domain for $\mathrm{p} 53$, another binding domain protein Rad51-dependent phosphorylation by $\mathrm{CdK}$ and two signaling domains nuclear, which also binds dss1 protein, which stabilizes BRCA2 and acts as a cofactor regulating the activity of homologous recombination. BRCA2 is essential for the activity of homologous recombination, mitotic checkpoint and location of the centrosome while cytokinesis, showing its importance in maintaining genomic stability (Wong, 1997; Smith, 1999; Deng and Brodie, 2000; Kojic, 2003, and Narod Foulkes, 2004; Niwa, 2009).

The genes BRCA1 and BRCA2 are involved in the repair of double breaks in DNA by homologous recombination, contributing to the integrity of the genome and maintenance of chromosomal stability. Although not much is known about the function of BRCA2, but it is known that deleterious mutations in both alleles may be a cause of Fanconi anemia-like or cause death during the embryonic period. Now for the BRCA1 gene, the homozygous in this case is always lethal during embryogenesis (D'Andrea, 2007).

In view of involvement in cellular processes critical to gene expression and genomic integrity, it is not difficult to understand that mutated forms of BRCA1 and BRCA2 lead to the onset of cancer. While these genes are presented in a nonfunctional, the cell becomes unable to repair breaks in double strands of DNA by homologous recombination (HR) and is more dependent on DNA repair pathways less efficient as the nonhomologous recombination and annealing single stranded (Turner, Tutt and Ashworth, 2004). The chromosomal instability can promote the carcinogenesis caused because of loss of function of these genes or by epigenetic silencing, germline mutation/somatic or increased transcription of genes that carrying a negative regulation of its expression (Fasano and Muggia, 2009).

The penetrance rate of mutations in BRCA1 and BRCA2 is still controversial, as there being a variation studies with different populations and between 
families and different family. However, the risk of developing breast cancer by age 70 is approximately 60 to $70 \%$ for BRCA1 mutation carriers and 45 to $55 \%$ for BRCA2. The risk of developing ovarian cancer by age 70 (including peritoneal carcinomas and the fallopian tubes) of $40 \%$ for patients with mutations in BRCA1 and 20\% for BRCA2 (Begg, 2008; Chen, 2007; Antoniou, 2003). The penetrance rate of this variability is not well understood today, but we know that reproductive factors, risks posed by particular mutations and other genetic modifiers, such as SNPs (single nucleotide polymorphisms) co-inherited, can be related (Gayther, 1995 and 1997; Antoniou, 2010).

The incidence of mutations in families at high risk varies significantly among different populations. Some mutations may be specific to a family or appear with high frequency in certain ethnic groups, which is called a founder effect (Kuska, 1997). The founder mutations are derived from genetically isolated populations that remain are not ethnically mixed, making a unique mutation usually still present and increase its frequency in this group. Many founder mutations have been reported in the literature (Thorlacius, 1996; Sarantaus, 2000; Vega, 2001). Classical examples are the mutations 185delAG and 5382insC in BRCA1 and 6174delT in BRCA2, affecting 2 to $2.5 \%$ of Ashkenazi Jews, often 10 to 50 times higher than in the general population (Szabo and King, 1997; Ferla, 2007). Sagi et al. (2010) proved that the Jews of Sephardic origin are also affected by founder mutations: A1708E in BRCA1, and IVS2 $+1 \mathrm{G} / \mathrm{A}$, in BRCA2. Besides the deleterious mutations, BRCA1 and BRCA2 genes may have polymorphisms that increase the predisposition to cancer by affecting gene expression, protein translation and genomic stability (Spurdle, 2000).

Mutations in these genes predispose carriers to the development of malignant tumors of the breast and, with a slightly lower frequency, with ovarian cancer and other associated tumors (melanoma, leukemia, lymphoma, fallopian tubes and peritoneal carcinomatosis for BRCA1 and male breast, prostate, pancreatic, colorectal, stomach, lymphoma and melanoma BRCA2), characterizing the Hereditary Breast and Ovarian Cancer 
(HBOC) (Ford, 1998; Johansson, 1999; Niello, 2004).

Typically, breast cancer in patients BRCA1 mutations in invasive ductal carcinoma is a high histologic and nuclear grade, high proliferation and type "triple negative" (negative for the expression of estrogen receptor (ER), progesterone receptor (PR) and HER2/neu (HER2)). Breast cancer attached to BRCA2 has almost similar morphology to sporadic, although a gene expression profile very different (Lakhani, 1998; Sobol, 2001; Perou, 2000; Sorlie, 2003).

\section{Implication of the biosynthesis of microRNAs in breast cancer}

Whereas it miRNAs carrying important roles in regulating gene expression associated with the stage and progression of cancer (Nelson et al., 2004), studies of the expression profile of miRNAs can also reveal changes in the regulatory processes that distinguish the appearance of cancer familial and sporadic breast cancer in young patients.

The miRNAs were discovered in 1993 in the nematode Caenorhabditis elegans (Lee et al., 1993) and represent a class of non-coding RNAs that have 18 to $24 \mathrm{bp}$ of nucleotides. Its role in gene regulation is its connection to a short sequence corresponding to the untranslated region 3' (3' UTR) of specific target mRNA, causing a block in protein translation or degradation of the mRNA target (Iorio et al, 2005). 600 miRNAs have been described belonging to the human species (Berezikov et al., 2005) and 1000 miRNA predicted by computational analysis (Pasquinelli et al., 2000, Bentwich et al., 2005). Since miRNAs may regulate more than one target, estimates indicate that a single miRNA can regulate more than $30 \%$ of protein coding genes in the human genome (Lewis et al., 2005), confirming its importance as a regulator of gene expression .

Most human miRNAs are transcribed from the intron region of genes coding or non-protein coding, while a minority may be transcribed from isolated sites in the genome region or 3'UTR of the mRNA (Bartel, 2004). miRNAs are transcribed by RNA polymerase II enzyme precursors in many RNAs, usually of several bases in length and secondary structure shaped loop (loop) called pri-miRNA. In the nucleus, the pri-miRNA is protected by a 
"cap" on the 5' and 3' poliadenilado in the region and presents a clamp that structure is cleaved by the enzyme complex Drosha (RNase III family member) and its cofactor DGCR8/Pasha producing a segment of approximately 70 nucleotides, called pre-miRNA (Cai et al, 2004). After being transported by exportin 5 out of the nucleus, the pre-miRNA is cleaved by another RNase III enzyme called Dicer, resulting in a fragment of double-stranded RNA of approximately 22 nucleotides. The RNA duplex originated by the action of Dicer contain the sense strand of the miRNA and tape known as anti-sense miRNA (Lau et al. 2001; Ricarte-Filho et al., 2009). As the complementarity in the 5' region between the two strands is unstable, there is a dynamic process in which the sense strand of the miRNA is associated with protein Argonaut (Ago) within the complex RISC (RNA-induced silencing complex), while the anti-sense strand is miRNA separated from the duplex. The single strand sense miRNA miRISC associated with the complex becomes able to regulate the expression of the mRNA target. Usually alignment miRNA - target mRNA is partly in the region 3' UTR which causes the suppression of protein translation. This alignment can be perfect in the central region of the transcript, causing breakage of the target mRNA (Hutvágner and Zamore, 2002; Negrini and Calin, 2008). There are currently four known proteins Ago encoded by the genome mammals and fish, and only the Ago2 appears to be capable of cleaving the target transcript in humans. The mechanisms involved in the inhibition of translation by miRNAs are not well understood (Martinez et al., 2002).

Relying on the homology between the terminal regions 5 ' of miRNA mature miRNAs can be grouped into families. This region has been preserved during evolution, implying its important role in the conservation of the mature form of miRNAs and the incorporation into the RISC complex formation miRISC (Brennecke et al., 2005). Considering its role in the recognition of the target mRNA, the 5' region of miRNA has also been used for the development of bioinformatics tools for the prediction of potential targets of miRNAs throughout the genome. With the help of these tools have already been predicted more than 
200 targets for each miRNA (Stahlhut and Slack, 2006).

The changed expressions of miRNAs in several types of tumors (Michael et al., 2003) indicates their participation as oncogenes (Hoffman et al. 2009), since such changes may affect the cell cycle and cell differentiation ( $\mathrm{Yu}$ et al. 2010). Furthermore, more than $50 \%$ of the genomic regions from which they originate miRNAs are located at chromosome fragile sites, which are presented deleted or amplified in cancer (Calin et al., 2004). Calin et al. (2002) provided the first evidence of the involvement of miRNAs in cancer, showing that the $13 \mathrm{q} 14$ region deleted in patients with chronic lymphocytic leukemia (CLL) contained sequences related to the expression of miR-15a and miR-16-1. In breast cancer, deregulation in the expression of miRNAs have been detected in metastatic cases and worse prognosis by suggesting important roles in oncogenesis and progression of breast cancer (Iorio et al. 2005; Silveri et al., 2006, Si et al., 2007). In studies with mammary tumor lines, miRNAs have been described as related to the aggressiveness of breast cancer and the sensitivity of human mammary tumor strains to anti-estrogen (Zhao et al., 2008). For example, overexpression of miR-10b promotes activation of protein RHOC through its target gene HOXD10, facilitating the processes of invasion and metastasis (Tan et al., 2009).

Whereas miRNAs seem to play an important role in mammary tumorigenesis, determining the profile of differential expression of miRNAs in young women, may help identify molecular markers that allow elucidate mechanisms involved in the aggressiveness of these tumors in patients with or without familial history.

\section{References}

Anders CK. Acharya CR. Hsu DS. Broadwater G. Garman K. Foekens JA. Zhang Y. Wang Y. Marcom K. Marks JR. Mukherjee S. Nevins JR. Blackwell KL. Potti A. Age- specific differences in oncogenic pathway deregulation seen in human breast tumors. PLoS ONE. 2;3(1):e1373. 2008.

Antoniou, A. et al. Average risks of breast and ovarian associated with BRCA1 or BRCA2 mutations detected in case Series unselected for family history: a combined analysis of 22 studies. American Journal of Human Genetics.72(5):1117-1130. 2003. 
Antoniou, A. et al. Common breast cancer susceptibility alleles and the risk of breast cancer for BRCA1 and BRCA2 mutation carriers: implications for risk prediction. Cancer Research. 70(23):9742-9754. 2010.

Bartel D.P. MicroRNAs: genomics. biogenesis. mechanism. and function. Cell. 116. 281-297. 2004.

Begg, C. B. et al. Variation on breast cancer risk among BRCa1/2 carriers. Journal of Clinical Oncology. 299(2):194-201. 2008.

Bentwich I, Avniel A, Karov Y, Aharonov R, Gilad S, Barad O, et al. Identification of hundreds of conserved and nonconserved human microRNAs. Nat Genet. 37(7):766-70. 2005.

Berezikov E, Guryev V, van de Belt J, Wienholds E, Plasterk R. H, Cuppen E. Phylogenetic shadowing and computational identification of human microRNA genes. Cell. 120(1):21-4. 2005.

Bertheau P, Steinberg SM, Cowan K e Merino MJ. Breast cancer in young women: clinic pathologic correlation. Semin Diagn Pathol, 16: 248-56. 1999.

Bochar, D. et al. BRCA1 is associated with a human SWI/SNF- related complex: linking chromatin remodeling to breast cancer. Cell. 102:257-265. 2000 .

Brennecke J. Stark A. Russell RB. Cohen SM. Principles of microRNA-target recognition. PLoS Biol. 3:e85. 2005.
Buller, R. E. et al. Association Between Nonrandom X-Chromosome Inactivation and BRCA1 Mutation in Germline DNA of Patients With Ovarian Cancer. Journal of the National Cancer Institute. 91:339-346. 1999.

Cai X, Hagedorn C. H, Cullen B. R. Human microRNAs are processed from capped. polyadenylated transcripts that can also function as mRNAs. RNA. 10:1957-66. 2004.

Calin GA. Dumitru CD. Shimizu M. et al. Frequent deletions and down-regulation of micro-RNA genes miR15 and miR16 at $13 \mathrm{q} 14$ in chronic lymphocytic leukemia. Proc Natl Acad Sci USA 99:15524-9. 2002.

Calin GA. Sevignani C. Dumitru CD. et al. Human microRNA genes are frequently located at fragile sites and genomic regions involved in cancers. Proc Natl Acad Sci USA 101:2999-3004 2004.

Chen, S.; Parmigiani, G. Meta-analysis of BRCA1 and BRCA2 penetrance. Journal of Clinical Oncology. 25(11):1329-1333. 2007.

D'Andrea, A. D. et al Biallelic inactivation of BRCA2 in Fanconi anemia. Science. 297:606-609. 2007.

Deng, C. X., Brodie, S. G. Roles of BRCA1 and its interacting proteins. Bioessays. 22(8):728-737. 2000.

Fasano, J.; Muggia, F. Breast cancer arising in a BRCA-mutated background: therapeutic implications from an animal 
model and drug development. Annals of Oncology. 20(4):609-614. 2009.

Ferla, R. et al. Founder mutations in BRCA1 and BRCA2 genes. Annals of Oncology. 18:93-98. 2007.

Fernandopulle SM, Cher-Siangang $\mathrm{P}$ e Tan PH. Breast carcinoma in women 35 years and younger: a pathological study. Pathology. Jun;38(3):219-22. 2006.

Ford, D. et al. Genetic heterogeneity and penetrance analysis of the BRCA1 and BRCA2 genes in breast cancer families. The Breast Cancer Linkage Consortium. American Journal of Human Genetics. 62:676-689. 1998.

Foxcroft LM, Evans EB e Porter AJ. The diagnosis of breast cancer in women younger than 40. Breast, 13: 297-306. 2004.

Gajdos C, Tartter PI, Bleiweiss IJ, Bodian $\mathrm{C}$ e Brower ST. Stage 0 to stage III breast cancer in young women. J Am Coll Surg, 190: 523-9. 2000.

Gayther, S. A. et al. Germline mutations of the BRCA1 gene in breast and ovarian cancer families provide evidences for a genotype-phenotype correlation. Nature Genetics. 11(4):428-433. 1995.

Gonzalez-Angulo AM. Broglio K. Kau SW. Eralp Y. Erlichman J. Valero V. Theriault R. Booser D. Buzdar AU. Hortobagyi GN. Arun B. Women age < or $=35$ years with primary breast carcinoma: disease features at presentation. Cancer. Jun 15;103(12):2466-72. 2005.
Hall, J. M. et al. Linkage analysis of early-onset familial breast cancer to chromosome 17q21. Science. 250:16841689. 1990.

Hartmann, L. C. et al. Efficacy of bilateral profilatic mastectomy in BRCA1 and BRCA2 gene mutation carriers. Journal of the National Cancer Institute. 93(21):1633-1637. 2001.

Hoffman AE. Zheng T. Yi C. Leaderer D. Weidhaas J. Slack F. Zhang Y. Paranjape T. Zhu Y. microRNA miR-196a-2 and Breast Cancer: A Genetic and Epigenetic Association Study and Functional Analysis. Cancer Res. 69(14):5970-7. Epub Jun 30. 2009.

Hutvágner G, Zamore P. D. A microRNA in a multiple-turnover RNAi enzyme complex. Science. 297(5589):2056-60. Epub Aug 1. 2002.

INCA. Instituto Nacional do Câncer, $<$ http://www.inca.gov.br>. 2010.

Iorio M. V, Ferracin M, Liu C. G, Veronese A, Spizzo R, Sabbioni S, Magri E, Pedriali M, Fabbri M, Campiglio M, Menard S, Palazzo J. P, Rosenberg A, Musiani P, Volinia S, Nenci I, Calin G. A, Querzoli P, Negrini M e Croce C. M. MicroRNA gene expression deregulation in human breast cancer. Cancer Res. Aug 15;65(16):7065-70. 2005.

Iorio M. V, Ferracin M, Liu C. G, Veronese A, Spizzo R, Sabbioni S, Magri E, Pedriali M, Fabbri M, Campiglio M, Menard S, Palazzo J. P, Rosenberg A, Musiani P, Volinia S, Nenci I, Calin G. A, Querzoli P, Negrini M e Croce C. M. MicroRNA gene expression deregulation 
in human breast cancer. Cancer Res. Aug 15;65(16):7065-70. 2005.

Johansson, $O$. et al Incidence of malignant tumours in relatives of BRCA1 and BRCA2 germline mutation carriers. European Journal of Cancer. August;35(8):1248-1257. 1999.

Joslyn SA. Radiation therapy and patient age in the survival from early-stage breast cancer. Int J Radiat Oncol Biol Phys, 44: 821-6. 1999.

Kojic, M. et al. The BRCA2-interacting protein DSS1 is vital for DNA repair, recombination, and genome stability in Ustilago maydis. Molecullar Cell. 12(4):1043-1049. 2003.

Kuska, B. et al. Researchers expand genetic epidemiology of BRCA genes. Journal of the National Cancer Institute.89:844-845. 1997.

Lakhani, S. R. et al. Multifactorial analysis of differences between sporadic breast cancers and cancer involving BRCA1 and BRCA2 mutations. Journal of the National Cancer Institute. 90:1138-1145. 1998.

Lau N.C, Lim L.P, Weinstein E. G. Bartel DP. An abundant class of tiny RNAs with probable regulatory roles in Caenorhabditis elegans. Science, 294:858-862. 2001.

Le Page, F. et al. BRCA1 and BRCA2 are necessary for the transcription-coupled repair of the oxidative 8-oxoguanine lesion in human cells. Cancer Research. 60:5548-5552. 2000.
Lee RC, Feinbaum RL, Ambros V, The C. elegans heterochronic gene lin-4 encodes small RNAs with antisense complementarity to lin-14. Cell.75(5):843-54. 1993.

Lewis B. P, Burge C.B, Bartel D. P. Conserved seed pairing. often flanked by adenosines. indicates that thousands of human genes are microRNA targets. Cell. 120(1):15-20. 2005.

Martinez J, Patkaniowska A, Urlaub $\mathrm{H}$, Lührmann R, Tuschl T. Single-stranded antisense siRNAs guide target RNA cleavage in RNAi. Cell. Sep 6;110(5):563-74. 2002.

Michael M. Z.. O'Connor. S. M.. van Holst Pellekaan. N. G.. Young. G. P. \& James. R. J. Reduced accumulation of specific microRNAs in colorectal neoplasia. Mol. Cancer Res. 1; 882-891. 2003.

Miki, Y. et al. A strong candidate for the breast and ovarian cancer susceptibility gene BRCA1. Science. 266:66-71. 1994.

Monteiro, A. N. A. et al. Evidence for a transcriptional activation function of BRCA1 C-terminal region. Proceedings of the National Academy of Sciences of the United States of America. 93: 13595-13599. 1996.

Narod, S. A. \& Foulkes, W. D. BRCA1 and BRCA2: 1994 and beyond. Nature Reviews. 4:665-676. 2004.

Negrini M, Calin G. A. Breast cancer metastasis: a microRNA story. Breast Cancer Res. 2008;10(2):203. Epub Mar 26. 2008. 
Nelson. P. T. et al. Microarray-based. high-throughput gene expression profiling of microRNAs. Nature Methods 1. 155-161. 2004.

Niell, B. L. et al. BRCA1 and BRCA2 founder mutations and the risk of colorectal cancer. Journal of the National Cancer Institute. January 96(1):15-21. 2004.

Niwa, T. et al. BRCA2 interacts with the cytoskeletal linker protein plectin to form a complex controlling centrosome localization. Cancer Science. 100(11):2115-2125. 2009.

Pasquinelli A. E, Reinhart B. J, Slack F, Martindale M. Q, Kuroda M. I, Maller B. et al. Conservation of the sequence and temporal expression of let-7 heterochronic regulatory RNA. Nature. 408(6808):86-9. 2000.

Perou, C. M. et al. Molecular portraits of human breast tumors. Nature. 406:747752. 2000.

Ricarte-Filho J. C, Fuziwara C. S, Yamashita A. S, Rezende E, da Silva M. J, Kimura ET. Effects of let-7 microRNA on cell growth and differentiation of papillary thyroid cancer. Transl Oncol Dec; (2): 236-41. 2009.

Sarantaus, L. et al. Multiple founder effects and geographical clustering of BRCA1 and BRCA2 families in Finland. European Journal of Human Genetics. 8:757-763. 2000.
Scully, R. et al. Association of BRCA1 with RAD51in mitotic and meiotic cells. Cell. 88:265-275. 1997a.

Scully R. et al. BRCA1 is a component of the RNA polymerase II holoenzyme. PNAS. 94(11):5605-5610.1997b.

Si M-L. Zhu S. Wu H. Lu Z. Wu F and Mo Y-Y. miR-21-mediated tumor growth. Oncogene. 26. 2799-2803. 2007. Sidoni A, Cavaliere A, Bellezza G, Scheibel M e Bucciarelli E. Breast cancer in young women: clinicopathological features and biological specificity. Breast. Aug;12(4):247-50. 2003.

Silveri L, Tilly G, Vilotte J. L e Le Provost F. MicroRNA involvement in mammary gland development and breast cancer. Reprod Nutr. 46(5):549-56. 2006.

Smith, P. D. et al. Novel p53 mutants selected in BRCA-associated tumors which dissociate transformation suppression from other wild-type p53 functions. Oncogene. 18:2451-2459. 1999.

Sobol, H. et al. Accessing the risk of BRCA1-associated breast cancer using individual morphologic criteria. Histopathology. 38:378-379. 2001.

Sorlie, T. et al. Reported Observation of breast tumor subtypes in independent gene expression data sets. Proceedings of the National Academy of Sciences. 100(14):8418-8423. 2003.

Spurdle, A. B. et al. CYP17 promoter polymorphism and breast cancer in Australian women under age forty years. 
Journal of the National Cancer Institute. 92:1674-1681. 2000.

Stahlhut Espinosa C E, Slack F. J. The role of microRNA in Cancer. Yale $\mathbf{J}$ Biol Med. Dec;79(3-4):131-40. Review. 2006.

Szabo, C. I.; King, M. C. Inherited breast and ovarian cancer. Human Molecular Genetics. 4:1811-1817. 1995.

Tan Y, Zhang B, Wu T, Skogerbø G, Zhu X, Guo X, He S, Chen R.Transcriptional inhibiton of Hoxd4 expression by miRNA-10a in human breast cancer cells. BMC Molecular Biology 0:12. 2009.

Tavtigian, S. V. et al. The complete BRCA2gene and mutations in chromosome 13q-linked kindreds. Nature Genetics. 12:333-337. 1996.

Thorlacius, S. et al. A single BRCA2 mutation in male and female breast cancer families from Iceland with varied cancer phenotypes. Nature Genetics. 13:117-119. 1996.

Turner, N.; Tutt, A.; Ashworth A. Hallmarks of BRCAness in sporadic cancers. Nature Reviews, Cancer. 4(10):814-819. 2004.

Vega, A. et al. The R71G BRCA1 is a founder Spanish mutation and leads to aberrant splicing of the transcript. Human Mutation. 419:1-6. 2001.

Venkitaraman, A. R. Cancer susceptibility and the functions of BRCA1 and BRCA2. Cell. 108:171-182. 2002.
Walker RA, Lees E, Webb MB e Dearing SJ. Breast carcinomas occurring in young women ( $<35$ years) are different. Br J Cancer. Dec;74(11):1796-800. 1996.

Wang, Y. et al. BASC, a super complex of BRCA1-associated proteins involved in the recognition and repair of aberrant DNA structures. Genes \& Development. 14:927-939. 2000.

Wong A. K. et al. Rad51 interacts with the evolutionarily conserved BRC motifs in the human breast cancer susceptibility gene BRCA2. The Journal of Biological Chemistry. 272:31491-31494. 1997.

Wooster, R. et al. Identification of the breast cancer susceptibility gene BRCA2. Nature. 378:789-792. 1995.

Wooster, R. et al. Localization of a breast cancer susceptibility gene (BRCA2) on chromosome $13 \mathrm{q}$ by genetic linkage analysis. Science. 265:2088-2090. 1994.

$\mathrm{Wu}, \mathrm{L}$. C. et al. Identification of a RING protein that can interact in vivo with the BRCA1 gene product. Nature Genetics. 14:430-440. 1996.

$\mathrm{Wu}, \mathrm{L}$. C. et al. Identification of a RING protein that can interact in vivo with the BRCA1 gene product. Nature Genetics. 14:430-440. 1996.

$\mathrm{Xu}, \mathrm{X}$. et al. Centrosome amplification and a defective G2-M cell-cucle checkpoint induce genetic instability in BRCA1 exon 11 isoform-deficient cells. Molecullar Cell. 3:389-395. 1999.

Yarden, R. I. et al. BRCA1 regulates the G2/M checkpoint by activating Chk1 
kinase upon DNA damage. Nature Genetics. 30(3):285-289. 2002.

Yu F. Deng H. Yao H. Liu Q. Su F. Song E. Mir-30 reduction maintains selfrenewal and inhibits apoptosis in breast tumor-initiating cells. Oncogene. May 24. [Epub ahead of print] 2010.

Zhao J . J , Lin J, Yang H, Kong W, He L. e Ma X. Coppola D. Cheng JO. MicroRNA-221/222 negatively regulates $\mathrm{ER} \alpha$ and associates with tamoxifen resistance in breast cancer. J Biol Chem. [Epub ahead of print]. 2008. 